can not." I had, originally, added a sentence to the effect that, if $\gamma$ be taken equal to $\beta$, Van der Waals's result would at once be obtained. But I struck it out as irrelevant, because the discussion turned mainly upon the question of the value of the free path at a volume nearly equal to the critical volume. Here Van der Waals expressly recognized that his $b$ must be diminished in value. From my point of view, $\beta$ (having been determined once for all) is unchangeable; while $\gamma$ is essentially less than $\beta$, possibly even negative.

Prof. Korteweg takes a different view, and says that the "true" formula is obtained by the process above hinted at:-i.e. by putting (with the preceding notation) $\gamma=\beta$.

4. Prof. Korteweg speaks of the equation written above as "quite worthless." But, in all this discussion, where the rival expressions differ only by the introduction or rejection of terms of the order $\beta^{2} / v^{2}$; which, according to Prof. Korteweg, make an equation "true" or "quite worthless" as the case may be :-are we not introducing an error, of that order at least, in calmly writing

$$
p_{1}=p+\frac{a}{v^{2}}
$$

instead of some such expression as

$$
p_{1}=p+\frac{a}{v(v+a)} ?
$$

We have, fortunately, one practical test at hand to help in the decision of such questions. The introduction of the form last written, certainly more likely to be approximate than the first, renders the "quite worthless" equation capable of at least fairly representing the results of Andrews. The "true" equation, we know, does not represent them.

Edinburgh, 21/12/91.

$$
\text { P. G. TAIT. }
$$

\section{ON THE RELATION OF NATURAL SCIENCE} TO ART.1

\section{I.}

$\mathrm{W}^{\mathrm{E}}$

are assembled to-day in annual commemoration of a man whose marvellous breadth of view and extraordinary variety of interests are each time a fresh surprise to us. It seems incredible that the same hand could have penned the "Protogea" and the State-paper adjudging the Principality of Neufchâtel to the King of Prussia; or that the same mind could have conceived the infinitesimal calculus and the true measure of forces, as well as the pre-established harmony and the "Theodicea." A closer examination, however, reveals a blank in the universality of his genius. We seek in vain for any connection with art, if we except the Latin poem composed by Leibnitz in praise of Brand's discovery of phosphorus. We need hardly mention that his "Ars Combinatoria" has nothing to do with the fine arts. In his letters and works, observations on the beautiful are few and far between ; once he discusses more at length the pleasure excited by music, the cause of which he attributes to an equable, though invisible, order in the chordal vibrations, which "raiseth a sympathetic echo in our minds." However, the world of the senses had little reality for Leibnitz. With his bodily eye he saw the Alps and the treasures of Italian art, but they conveyed nothing to his soul. $\mathrm{He}$ was indifferent to beauty; in short, we never surprise this Hercules at Omphale's distaff.

The same neglect, at least of sculpture and painting,

1 An Address delivered by E. du Bois-Reymond, M.D., F.R.S., at the annual meeting of the Royal Academy of Setences of Berlin in commemoration of Leibnitz, on July 3,1890 . Translated by his daughter. This Address was first printed in the weekly reports (Sitsungsberichte) of the Berlin Academy, then in Dr. Rodenberg's Dentsche Kundschau, and lastly it was Academy, then in Dr. Rodenberg's Dentsche $R$ nundschazt, and lastly it was
published as a separate pamphlet by Veit and Co., at Leipzig, 1891.

$$
\text { NO. I I } 57 \text {, VOL. } 45]
$$

strikes us in Voltaire, who as polyhistorian can in some measure compare with Leibnitz. We are obliged to descend as far as the third generation-that is, to Diderot in France, to Winckelmann and Lessing in Germanybefore we meet with a decided interest in the fine arts, and an appreciation of the part they play in the progress of civilization.

The period thus defined, though it excels in science, shows with few exceptions a falling-off in the fine arts. On considering the historical development of these two branches of human productiveness, we find no correspondence whatever between their individual progress. When Greek sculpture was in its prime, science scarcely existed. True, Lionardo's gigantic personality, which combines the immortal artist with the physicist of high rank, towers at the beginning of the epoch generally known in the history of art as the Cinquecento. Still, he was too far in advance of his age in the latter capacity to be cited as an example of simultaneous development in art and science ; so little that Galilei was born the day of Michael Angelo's death. The mutual development of art and science at the commencement of our century is, I believe, merely a casual coincidence; moreover the fine arts have since been at the best stationary, whereas science strides on victoriously towards a boundless future.

In fact, both branches differ too widely for the services rendered to science by art, and vice vers $\hat{a}$, to be other than external. " Nature," Goethe very truly observed to Eckermann-little thinking how harshly this remark reflects on part of his own scientific work-" Nature allows no trifling; she is always sincere, always serious, always stern; she is always in the right, and the errors and mistakes are invariably ours." Fully to appreciate the truth of this, one must be in the habit of trying one's own hand at experiments and observations, while gazing in Nature's relentless countenance, and of bearing, as it were, the tremendous responsibility incurred by the statement of the seemingly most insignificant fact. For every correctly interpreted experiment means no less than this: whatever occurs under the present circumstances, would have occurred under the same conditions before an infinite negative period of time, and would still occur after an infinite positive period. Only the mathematician, whose method of research has more in common with that of the experimenter than is generally supposed, experiences the same feeling of responsibility in presence of Nature's eternally inviolable laws. Both are sworn witnesses before the tribunal of reality, striving for knowledge of the universe as it actually is, within those limits to which we are confined by the nature of our intellect.

However, there is a compensation for the philosopher, labouring under this anxious pressure, in the consciousness that the slightest of his achievements will carry him one step beyond the highest reached by his greatest predecessor; that possibly it may contain the germ of vastly important theoretical revelations and practical results, as Wollaston's lines contained the germ of spectral analysis; that, at any rate, such a reward is not only in the reach of a born genius, but of any conscientious worker; and, finally, that science, by subduing Nature to the rule of the human intellect, is the chief instrument of civilization. No real civilization would exist without it, and in its absence nothing could prevent our civilization, including art and its master-works, from crumbling away again hopelessly, as at the decline of the ancient world.

This consciousness will also make up to the philosopher for the thoughtlessness of the multitude, who, while enjoying the benefits thus lavished upon them, hardly know to whom they owe them. The country rings with the name of every fashionable musical virtuoso, and cyclopædias insure its immortality. But who repeats the name of him who achieved that supreme triumph of the inventive intellect - to convey through a copper wire across 
far-stretching countries and over hill and dale the sound of the human voice as though it spoke in our ear?

"Life is earnest, art is gay": this saying of Schiller's remains as true if we substitute science for life. Art is the realm of the beautiful; its productions fill us with an enjoyment, half sensuous, half intellectual ; it is, therefore, a realm of liberty in the widest sense. No rigid laws are enforced in it; no stern logic binds the events of the present to those of the past and future; no certain signs indicate success ; blame and praise are distributed by the varying taste of ages, nations, and individuals, so that the glorious Gothic church architecture came to be derided by the eighteenth century. In art, the definition of genius as a talent for patience does not hold good. Its creations, once brought forth in a happy hour of revelation, stir our souls with elementary force, and scorn al abstruse explanations, subsequently forced upon them by art criticism. Whoever accomplishes such a feat also ministers in a sense to the cares and troubles of humanity. Unfortunately, the nature of things does not allow such fruit to ripen at all seasons; at one time, in one direction, the culminating point will be reached, and then age after age will strive in vain to emulate the past. The finest rsthetic theories can neither carry the individual beyond the limits of his own natural powers, nor retrieve the fortunes of a declining period. Of what use has been the recent strife in the artistic world between naturalists and idealists? Has it protected us from the frequently almost intolerable extravagances of the latter? There is an attraction in every boldly advanced novelty which the common herd is unable to resist, and which will invariably triumph till antiquated ideas are somehow supplanted by fresh ones, or by the lofty rule of some irresistibly superior personality. Nor can science in the stricter sense come to the aid of art; and thus, strangers at heart, without materially influencing each other, each seeks its own way: the former advancing steadily, though irregularly; the latter slowly fluctuating like a majestic tide. Those unfamiliar with science are apt to recognize the supreme development of our mental faculties in art alone. Doubtless this is a mistake; yet human intellect shines brightest where glory in art is coupled with glory in science.

We may notice something here which is similar to what occurs in practical ethics. The more corrupt the morals of an age or nation, the more we find virtue a favourite topic. The flood of æsthetic theories rises highest when original creative power is at its lowest ebb. Lotze, in his "History of Æsthetics in Germany," " gives a wearying and discouraging account of such fruitless efforts. Philosophers of all schools have rivalled in abstract definitions of the essence of beauty. They call it unity in multiplicity, or fitness without a purpose, or unconscious rationality, or the transcendant realized, or the enjoyment of the harmony of the absolute, and so forth. But all these properties, which are supposed to constitute the beautiful, have no more to do with our actual sensation of it than the vibrations of light and sound with the qualities they bring to our perception. Indeed, it would be vain to attempt to find one term equally fitted to describe all the varieties of the beautiful: the beauty of cosmos as contrasted with chaos, of a mountain prospect, a symphony, or a poem, of Ristori in Medea, or a rose ; or even, taking the fine arts alone, the beauty of the Cologne Cathedral, the "Hermes" of Praxiteles, the Madonna Sistina, a picture of still-life, a landscape, a genre piece, or a Japanese flower design; not to mention the questionable custom which permits us in German to speak of a beautiful taste or a beautiful smell. Let us rather admit that here, as so often, we meet with something inexplicable in our organization; something inexpressible, though not the less distinctly

$$
\text { I Munich, I868. }
$$

felt, without which life would offer a dull and cheerless aspect.

In an essay of Schiller's there is a disquisition on physical beauty. ${ }^{1} \mathrm{He}$ distinguishes between an architectural beauty and a beauty which emanates from grace. I attacked this æsthetic rationalism, to which the last century was strongly addicted, twenty years ago on a similar occasion in a lecture on Leibnitz's ideas in modern science. I ventured to assert that "the attraction which physical beauty exerts on the opposite sexes can as little be explained as the effects of a melody." " On reflection, it seems, indeed, incomprehensible why one distinct shape, which, according to Fechner, might be represented by a plain algebraic equation between three variables, should please us beyond a thousand other possibilities. The reason can be traced from no abstract principle, no rules of architecture, not even from Hogarth's line of beauty. A year after this remark was made, Charles Darwin published his "Descent of Man," in which the principle of sexual selection, only cursorily treated in the "Origin of Species," is fully expounded, and pursued in all its bearings. I remember vividly how, in a discussion with Dove as to the necessity of admitting a vital force, he embarrassed me by the objection that in the organic world luxury occurs, for example, in the plumage of a peacock or a bird of Paradise; while in inorganic nature Maupertuis's law of the minimum of action precludes such prodigality. Here was a solution to the problem, allowing that one might attribute to animals a certain sense of beauty. The gorgeous nuptial plumage displayed by male birds may have been acquired through the preference of the female for more highly ornamented suitors, a progeny of constantly increasing brilliancy of colouring being thus obtained. Male birds of Paradise have been observed to vie in showing off their beauty before the females during courtship. The power of song in nightingales might be attributed to the same cause, the female in this case being more susceptible to the charms of melody than to those of brilliant colouring. Darwin goes on to observe that, in the human race likewise, certain sexual characteristics, such as the imposing beard in man and the lovely tresses in woman, might have been acquired through sexual selection. ${ }^{3}$ It is a wellknown fact that, by the repeated introduction of handsome Circassian slaves into aristocratic Turkish harems. the original Mongol type in many cases has been remarkably ennobled. And carrying the same principle further, we may find therein an explanation for the fascination which female beauty has for man. According to our present views, the first woman was not made of a rib taken out of the first man-a process fraught with morphological difficulties. It was man himself who, in countless generations, through natural selection, fashioned woman to his own liking, and was so fashioned by her. This type we call beautiful, but we need only to cast a glance at a Venus by Titian, or one by Rubens-let alone the different human races-to recognize how little absolute this beauty is.

If one kind of beauty could be said to bear analyzing better than another, it is what might be termed mechanical beauty. It is noticed least, because it escapes all but the practised eye. This kind of beauty may belong to machines or physical apparatus, each part of which is exactly fitted to its purpose in size, shape, and position. It answers more or less to the definition of "unconscious rationality," our satisfaction

I "Ueber Anmuth und Würde."

2 The author's "Collected Addresses, \&c.," vol, i., pp. 49, 50, Leipzig, 1886.

3 The author is not unaware of Mr. Wallace's attack on Darwin's,explanation of the brilliant plumage of male birds by the females' preference, and of the discussion arisen between him and Messrs. Poulton. Pocock, and Peckham. This was not the proper place to enter into it, the less so as, whatever may be its outcome, the author's conclusion from the theory of sexual selection would remain unaltered. 
evidently proceeding from an unconscious perception of the right means havin 5 been employed to combine solidity, lightness, and, if necessary, mobility, with the greatest possible profit in the transmission of force, and the smallest waste of material. A driving-belt is certainly neither attractive nor unattractive; but it pleases the "visus eruditus" to see a connecting-rod thicken from the ends towards the middle, where it has to bear the greatest strain. Of course this kind of beauty is of recent origin. I remember Halske telling me that, ${ }^{-}$as regards the construction of physical and astronomical instruments, it was, to his knowledge, first understood and established as a principle in Germany by Georg von Reichenbach in Munich. Berlin and Munich workshops produced instruments of perfect mechanical beauty at a time when those supplied by France and England were still often disfigured by aimlessly ornamented columns and cornices, unpleasantly recalling the impure features of Rococo furniture and architecture.

I forget which French mathematician of the last century, in sight of the cupola of St. Peter's at Rome, tried to account for the sense of perfect satisfaction it gives to the eye. He measured out the curves of the cupola, and found that, according to the rules of higher statics, its shape supplies the exact maximum of stability under the given circumstances. Thus Michael Angelo, guided by an unerring instinct in the construction of his model (the cupola was not erected till after his death), unconsciously solved a problem the true nature of which he could hardly have understood, and which was even beyond the reach of the mathematical knowledge of his age. Apparently, however, there are several roots to this equation of beauty; at least there is one other type, for which I quote the cupola of Val de Grâce in Paris, which, if not as imposing, is quite as gratifying to the eye, as Michael Angelo's.

It will be observed that in this case mechanical beauty becomes part of the art of architecture; and instances of this kind are daily growing more frequent, our modern iron structures being more favourable to its display than stone buildings. In the Eiffel Tower we see mechanical beauty struggling with the absence of plastic beauty. On this occasion it was probably revealed for the first time to many who hitherto had no opportunity of experiencing its effect. It is certainly not wanting in the new Forth Bridge. There is no doubt, however, that in stone structures too, together with much that pleases from habit or tradition, there are certain features which evidently attract through mechanical beauty-such as the outline of the architectural members of a building, or the gentle swelling and tapering of the Doric column towards the top, and its expansion in the echinus and abacus; and there are others which offend a refined taste through the absence of this beneficial element, such as the meaningless ornamentations of the Rococo style.

Even in organic nature mechanical beauty prevails to such an extent that it transforms many objects into a source of delight and admiration to the initiated, which are naturally repulsive to the untrained eye. Anatomists recounize it with pleasure in the structure of the bones, esfecially of the joints. In their opinion the "Dance of Death" outrages good taste from more reasons than because it differs from the classical conception of death Mechanical beauty was already perceived by Benvenuto Cellini in the skeleton, much to his credit ; and but for our imperfect knowledge, it would invest with its glory every organic form, down to the inhabitants of the aquarium, even under the very microscope. According to Prof. Schwendener, even plants are constructed on the same principle of fitness combined with thrift; and something of this we feel at sight of a spreading oak-tree, proudly distending its vigorous branches towards air and sunlight.

NO. I I 57 , voL. 45]
Again, our appreciation of the forms of animals, especially of noble breeds, is greatly influenced by mechanical beauty. The greyhound and the bulldog. the full-bred race-horse and the brewer's dray-horse, the Southdown and the Merino sheep, the Alpine cattle and the Dutch milch-cow, all are beautiful in their kind; even though a bulldog or a Percheron may appear ugly to the uninitiated, because in each the type of the species has been modified to the utmost degree of fitness.

Though science is unable, as we have seen, to check the occasional decline of art and inspire it with fresh vigour, yet it renders invaluable services of a different kind to artists, by increasing their insight, improving their technical means, teaching them useful rules, and preserving them from mistakes. I do not allude to anything so primitive as the manufacture of colours or the technique of casting in bronze; the less so, as, curiously enough, our modern colours are less durable than those of entirely unscientific ages, and the unsurpassed thinness of the casting of Greek bronzes is regarded as a proof of their authenticity. Nor does it seem necessary to recall the notorious advantages of this kind for which art is indebted to science. Linear perspective was invented by Lionardo and Dürer - artists themselves. It was followed by the laws of reflection-unknown to ancient painters, is would appear from the Pompeian frescoes of Narcissusand by the geometrical construction of shadows. The rainbow, which had better not be attempted at all, has been sinned against cruelly and persistently by artists, in spite of optics. Statics furnished the rules of equilibrium, so essential to sculptors. Aërial perspective, again, owes its development to painters chiefly of northern climates.

But to this fundamental stock of knowledge the pro. gress of science has added various new and important acquisitions, which philosophers, some of first-rate ability, have endeavoured to place within the reach of artists. The great masters of by-gone ages were taught by instinct to combine the right colours, as women of taste, according to John Müller, always know how to blend the right shades in their dress; and Oriental carpet-weavers have not been behindhand with them in that respect. But the reason why they unconsciously succeed was not revealed till the elder Darwins, Goethe, Purkinye, John Muiller, and others, called into existence a subjective physiology of the sense of sight. A member of this Academy, Prof. von Bricke, in his "Physiology of Colours" and "Fragments from the Theory of the Fine Arts in relation to Industrial Art," 2 treats these subjects with such intimate knowledge as could only be obtained by one who enjoyed the rare advantage of combining physiological learning with an artistic education acquired in his father's studio. In France, Chevreul pursued similar aims. Even Prof. von Helmholtz, in his popular lectures, has devoted his profound knowledge of physiological optics, to the service of art, which already owes him important revelations on the nature of musical harmony. Amongst other things, he explained the relation between the different intensities of light in objects of the actual world and those on the painter's palette ; and pointed out the means by which the difficulties arising therefrom may be overcome. ${ }^{3}$ Thus painters, as von Briicke remarks, have it in their power to reproduce the dazzling effect of the disk of the sun by imitating the irradiation - a defect of our visual perception the true nature of which was recognized by von Helmholtz. An example of this, interesting through its boldness, is the lovely Castell Gandolfo in the Raczynski gallery.

There are so many and striking instances of such imperfections of the human eye that, notwithstanding its marvellous capabilities, von Helmholtz has observed that "he would feel himself justified in censuring most severely

I 2nd edition, Leipzig, $1887 . \quad{ }^{2}$ Leipzig, 1877

3 Prof. von Helmholtz, "Collected Essays and Addresses," vol. ii., Brunswick, 1884 . 
the careless workmanship of an optician who offered him for sale an instrument with similar defects, and that he would emphatically refuse to take it." The eye being the chief organ of artists, its defects are of great importance in art and its history, and artists would do well to inform themselves, not only on these defects in general, but more particularly on those which they, in their own persons, are subject to; for, as Bessel remarked of astronomical instruments, "an error once well ascertained ceases to be an error."

Our conception of the stars as stars, in the shape adopted symbolically by decorative art, is caused by a defect of the eye closely related to irradiation; stars being luminous spots in the sky without rays, as they actually appear to a privileged few. Prof. Exner, whose line of thought we shall repeatedly cross in the course of these reflections, justly remarks that to this imperfection the stars conferred by Sovereigns as marks of distinction owe their origin, and star-fishes their name, even since Pliny's time. The different varieties of halo, however, are more probably free-born children of our fancy - from the Byzantine massive golden disk, down to the mild phosphorescence proceeding from holy heads and in Correggio's "Night "from the entire child, which illumines the scene with a light of its own. According to Prof. Exner, glories of the latter description are derived from the radiance which surrounds the shadow of one's own head in the sunshine on a dewy meadow, and which in fact has always been compared to halos in religious pictures. This phenomenon even misled Benvenuto Cellini into the pious delusion that it was a gift granted him individually from above, and a reflection of his visions, such as Moses brought down from Mount Sinai. ${ }^{1}$

Certain otherwise quite inexplicable peculiarities which disfigure the later works of the distinguished landscapepainter Turner have also been traced to defects of the eye by Dr. Richard Liebreich. ${ }^{2}$ Clouded lenses or a high degree of astigmatism might easily lead a painter to distort or blur objects he was copying from nature. Donders's stenopeic spectacles or cylindrical spectacles, as the case might be, would prove as useful to such an artist as concave glasses to the shortsighted.

The singularities of another English painter, Mulready, are accounted for by Dr. Liebreich through discoloration of the lens from old age. Another defect of the eyecolour-blindness-ought to be mentioned here, which in its milder forms is of frequent occurrence, and even belongs to the normal condition of the eye on the borders of the field of vision. It corresponds in the domain of hearing to the want of musical ear. Colour-blindness was known long ago, but has been inquired into with redoubled zeal latterly, partly with regard to its general connection with chromatics, partly on account of its serious practical consequences in the case of sailors, railway officials, and, as Dr. Liebreich adds, of painters. Both colour-blindness and want of ear are inborn defects, for which there is no remedy. A colour-blind artist is, however, better off than a musician without an ear, if such a one were imaginable, for, even if he neglected the modelling stick and the chisel, he might still seek his fortune in the designing of cartoons.

It is difficult to determine the particular point where optical knowledge ceases to be of use to artists. None will repent having studied the laws of the movement of the eyes, the difference between near and distant vision, and the observations on the expression of the human eye contained in John Müller's early work on "Comparative Physiology of Sight." Yet it must be admitted that a painter may paint an eye exceedingly well without ever having heard of Sanson's images, which cause the soft lustre of a gentle eye as well as the fierce flash of an

1 "Vita di Benvenuto Cellini, scritta da lui medesimo," libro primo, cxxvii. Turner and Mulready : the Effect of certain Faults of Vision on Painting, \&c.." London, 1888.

NO. I I 57 , VOL. 45] angry one ; as little as the blue sky of a landscape painter will gain by his knowledge of the yellow brushes in every great circle of the heavenly vault which passes through the sun-a phenomenon which has remained unnoticed for countless ages, but has grown familiar to physiologists since Haidinger's discovery.

One point, however, where physicists seem to me not to have been sufficiently consulted, is the much-debated question of polychrome in ancient statues and architecture, and whether it should be adopted by modern art or not, Physical experiments teach that very intense illumination causes all colours to appear whitish; in the spectrum of the sun, seen immediately through the telescope, the colours vanish almost entirely, nothing remaining except a light yellow hue in the red end. As the colours grow whitish the glaring contrasts are softened, they blend more harmoniously. In the open air, therefore, our eye is not shocked by the scarlet skirt of the contadina, which recurs almost as invariably in Oswald Achenbach's Campagna landscapes, as the white horse in Wouvermanns's war scenes. The Greek statues and buildings may have looked well enough with their glaring decorations under the bright southern sky on the Acropolis or in the Poikile; in the dull light of our northern home, above all in closed rooms, they are somewhat out of place.

In another direction Wheatstone has added valuable information to the knowledge of painters and designers with his stereoscope. It demonstrates the fundamental difference which distinguishes binocular vision of near objects from monocular vision, as well as from binocular vision of objects so far removed that the distance between the eyes vanishes as compared with their distance. An impression of solidity can only be obtained by each eye getting a different view of an object, the two images being fused into one, so as to appear solid. A painter can therefore only express depth by shading and aërial perspective; he will never be able to produce the impression of actual solidity on his canvas. While Wheatstone's pseudoscope exhibits the unheard-of spectacle of a concave human face, Helmholtz's telestereoscope magnifies, as it were, the space between the eyes, and resolves a faroff range of woods or hills without aërial perspective into its different distances. Finally, Halske's stereoscope with movable pictures confirms old Dr. Robert Smith's explanation of the much-debated circumstance that the sun and moon on the horizon appear larger by almost a fifth of their diameter than when seen in the zenith, and reduces the problem to the other question: why the vault of the sky appears to us flattened instead of hemispherical.

However, the almost contemporary invention of photography was destined to be of vastly greater importance to the fine arts. It had always been the dream of artists as well as physicists to fix della Porta's charming pictures -a dream the realization of which did not seem quite impossible since the discovery of chloride of silver. One must have witnessed Daguerre's invention, and Arago's report of it in the Chamber of Deputies, to conceive the universal enthusiasm with which it was welcomed. Daguerre's method, being complicated and of restricted application, was soon cast into the shade by the one still essentially practised at the present day. However, it is worth recording that, when the first specimens, imperfect as they were, reached us from England, no one foresaw the inmense success in store for Talbotypes; on the contrary, the change from silver-coated plates to paper impregnated with the silver salt was received with doubt, and considered a retrogression.

Thus photography entered on its marvellously victorious career. With respect to art it promptly fulfilled what Arago had promised in its name. It not only facilitated the designing of architecture, interiors, and landscapes, and rendered the camera clara unnecessary 
even for panoramas, but also furnished many valuable hints with regard to light and shade, reflection and chiaroscuro, and the general means of reproducing as closely as possible on a level surface the raised appearance of solid forms. A competent judge of both arts might find it an interesting task to ascertain what share photography has had in the origin of the modern schools of painting, and in the manner of impressionists and pleinairists. It further taught landscape-painters to depict rocks and vegetation with geological and botanical accuracy, and to represent glaciers, which hitherto had been but rarely and never successfully attempted. It caught and fixed the changing aspect of the clouds, though only yielding a somewhat restricted survey of the heavens. It aided portrait-painters without exciting their jealousy; for, unable to rival them in representing the average aspect of persons, it only seized single, often strained and weary expressions, rendering almost proverbial the comparison between a bad portrait and a photographed face; nevertheless it supplied them on many occasions with an invaluable groundwork, lacking nothing but the animating touch of an artist's hand.

However, the recent progress of photographic portraiture claims the attention of artists in more than one respect. Duchenne and Darwin called into existence a new doctrine of the expression of the emotions; the former by galvanizing the muscles of the face, in order to imitate different expressions, the latter by inquiring into their phylogenetic development in the animal series. Both presented artists with photographs which quickly consigned to oblivion the copies hitherto employed for purposes of study in schools of art, dating chiefly from Lebrun; even the sketches in Signor Mantegazza's new work on "Physiognomy and Mimics" will scarcely enter into competition. On Mr. Herbert Spencer's suggestion, Mr. Francis Galton subsequently solved by the aid of photography a problem, which was previously quite as inaccessible to painters as the representation of an average expression to photographers. He combined the average features of the face and skull of a sufficient number of persons of the same age, sex, profession, culture, or disposition to disease or vice, in one typical portrait, which exhibits only those characteristic forms common to their various dispositions. This was effected by blending on one negative the faint images of a series of persons belonging to the same description. In the same manner, Prof. Bowditch, of Harvard Medical School, Boston, obtained the representative face or type of American students of both sexes, and of tramway conductors and drivers. In the latter instance, the intellectual superiority of the conductors over the drivers is plainly visible. How Lavater and Gall would have relished this!

Of course the average expression of a single person might be procured by similar means, if it were worth while summing up on the same plate repeated photographs of different expressions. Instantaneous photography, however, furnishes a welcome substitute for the average expression, by seizing with lightning swiftness the changing phases of the human countenance in their full vivacity. Here, again, pathology places itself at the disposal of art. M. Charcot has found that photographs of the convulsions and facial distortions of hysterical patients resemble our classical representations of the possessed. Raphael's realism in this respect is perhaps the most curious of all, being so much at variance with his idealistic nature. In the possessed boy of the "Transfiguration," a cerebral disease can be almost safely inferred from the Magendie position of the eves; and the circumstance, recently observed in New York, that the left hand is depicted in a spasm of athetosis, would accord well with this diagnosis. ${ }^{1}$

(To be continued.)

"Sachs and Petersen, "A Study of Cerebral Palsies," \&c., Joutnal of Nerrous and IYental Diseases, New York, May i8go.

\section{TELESCOPIC OBJECTIVES. ${ }^{1}$}

$\mathrm{I} \mathrm{T}$ is a frequent source of disappointment to observers, especially beginners, to find that their instruments fail to answer to the tests which are so commonly found in astronomical text-books: It may be that the instrument in question is really an imperfect one; but if it be the work of a maker of repute, it is more probable the fault lies in the absence of proper adjustment, more especially if, for some reason or other, no responsible person is able to superintend the final fixing in position. The information hitherto published on the subject of adjustment, and the phenomena which accompany the various defects of an objective, is very scanty ; and observers of all classes will therefore welcome the appearance of the little book recently issued by Messrs. T. Cooke and Sons, the wellknown firm of telescope makers The book is the best testimony that one could wish for as to their thorough knowledge of their business, and it abundantly demonstrates that they are worthy of the confidence which astronomers have long placed in them. The benefit of their wide experience is now available to all, and observers need no longer remain in doubt as to the quality of their objectives, or of the course to be pursued in tracing the defects to their proper sources.

For full particulars of the methods to be adopted we must refer our readers to the book itself, but many of the points touched upon are of great interest, considered simply as optical phenomena, and a brief reference to some of them may not be out of place.

It is a matter of common knowledge that, owing to the undulatory nature of rays of light, the image of a luminous point, such as a star, must always be a small disk, the diameter of which varies in inverse proportion to the aperture of the objective. This "spurious disk" is surrounded by a series of diffraction rings, which gradually diminish in intensity away from the centre.

The calculations of Sir George Airy ${ }^{2}$ show that the angular radii of the rings, in circular measure, are given by the formula $\frac{\lambda n}{2 \pi e}$, where $\lambda$ is the wave-length of the light-rays in question, $e$ the radius of the objective, and $n$ a constant which depends on the distance from the centre. The first dark ring occurs when $n=3.83$, the second when $n=7.14$, and the third when $n=1017$. Hence, the angular radius of the first dark ring, which is really the boundary of the spurious disk, may be easily derived from the formula $\frac{3.83 \times \lambda}{2 \pi e}$, or $\frac{\mathrm{I}^{\cdot} 22 \lambda}{2 e} \cdot$

The rings are brightest when $n=5 \cdot \mathrm{I}_{2}, 8.43$, and $\mathrm{II}^{\cdot} 6_{3}$, with intensities respectively about $1 / 57,1 / 240$, and $1 / 620$ of that at the centre.

If $s$ be the angular radius in seconds of arc, as viewed from the centre of the objective, the formula becomes

$$
n=\frac{2 \pi e s}{\lambda} \cdot \sin \mathbf{I}^{\prime \prime} \text {; }
$$

and if $\lambda$ for mean rays be taken as 000022 inch,

$$
n=x \cdot 3846 \times \text { es. }
$$

For the first dark ring, therefore,

$$
s=\frac{3.83}{1 \cdot 3846 e}=\frac{2 \cdot 76}{e} .
$$

Messrs. Cooke put these expressions in the form-

Angular diameter of first dark ring in circular measure $=\frac{2 \times I^{\cdot 22 \lambda}}{A}$,

$$
\text { Linear diameter of first dark ring }=\frac{2 \mathrm{~F} \times \mathrm{I} \cdot 22 \lambda}{\mathrm{A}}
$$

where $\mathrm{A}=$ aperture, and $\mathrm{F}=$ focal length.

For a square aperture the conditions are different, and

I "On the Adjustment and Testing of Telescopic Objectives." (T. Cooke and Snns, Buckingham Works, York.)

2 "Undulatory Theory of Optics," I877 edition, p. 80. 